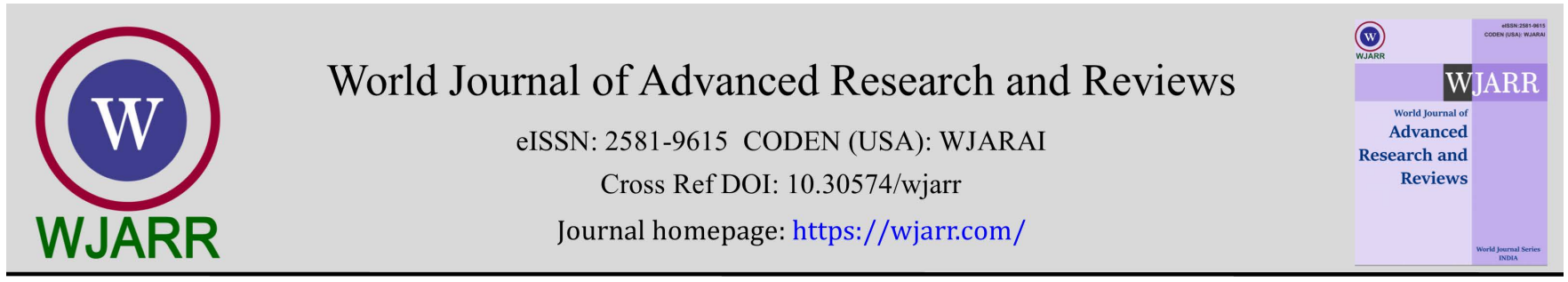

(RESEARCH ARTICLE)

\title{
Factors associated with cognitive developmental delay among infants attending Reproductive and Child Health clinics in Dar es salaam, Tanzania
}

\author{
Gudila Valentine Shirima ${ }^{1}$, Obadia Venance Nyongole 2*, Augustine Massawe ${ }^{2}$ and Gad Kilonzo ${ }^{2}$ \\ ${ }^{1}$ Department of pediatrics and child health, Muhimbili National Hospital. \\ ${ }^{2}$ School of Medicine, Muhimbili University of Health and Allied Sciences.
}

World Journal of Advanced Research and Reviews, 2021, 09(02), 179-191

Publication history: Received on 15 January 2021; revised on 14 February 2021; accepted on 16 February 2021

Article DOI: https://doi.org/10.30574/wjarr.2021.9.2.0060

\begin{abstract}
Background; Early child cognitive development is important throughout one's life span. It is estimated that more than 200 million children under five years of age fail to achieve full cognitive development in the world and $80 \%$ of them are in south Asia and sub-Sahara-Africa. Genetic and environmental factors play a role in early child development (ECD). Most of the ECD occurs in the first 2years of life, but largely during infancy. Malnutrition, poverty and poor health care to children have been found to have association with poor cognitive development and create a vicious cycle of poverty. This study gives the proportion and factors that are associated with infants' cognitive developmental delay in our setting. Knowing these factors enhance early intervention to break the viscious cycle.This study aimed to determine the proportion and factors associated with cognitive developmental delay among infants attending RCH clinics in Dar es Salaam.
\end{abstract}

Patients/ Material and Methods; This was a health facility based descriptive cross-sectional study conducted by using a structured data collecting tool done in three health centers in Dar es Salaam from July to December 2012. A two- stage sampling technique and Lottery were used to get the health centers. The data were analyzed using SPSS software by Pearson's chi-square, Fisher exact test and logistic regressions.

Results; A total of 350 infants were assessed for cognitive development in a period of six months. Male infants were the majority by $50.6 \%$. Our study Participants aged 1to 12 months with a mean (SD) of 7.26 (3.43) months with their birth weight ranging from 1.3 to $4.6 \mathrm{~kg}$ with mean (SD) of $3.11(0.50) \mathrm{kg}$. The Proportion of infants with cognitive developmental delay was $12.3 \%$. Age of the child, caretakers and wasting were significantly associated with cognitive developmental delays even after adjusting for confounders. Infants aged less than 6months were 14 times more likely to have cognitive developmental delay compared to those aged six months and above (adjusted oddis ratio\{aOR=14; 95\%CI 5.3-38.3, $\mathrm{P}<0.001\}$ ). Infants cared by assistant caretakers especially during day-time, were 12 times more likely to have cognitive developmental delay compared to infants who stayed with their mothers (aOR=12.1; 95\%CI 3.0-53, $\mathrm{P}=0.001$ ). Wasted infants were 4 times more likely to have cognitive developmental delay (aOR=3.9; 95\%CI 1.1-13.3, $\mathrm{P}=0.032$ ) compared to infants with good nutritional status.

Conclusion; The proportion of cognitive developmental delay among infants attending Reproductive and Child Health( $\mathrm{RCH}$ ) clinics in Dar es Salaam was 12.3\%. Young age of the child, use of other caretakers in absence of the mother, and wasting were associated with cognitive developmental delays. Infants need Mothers to spend time with them and prevention of malnutrition plays a role in cognitive development.

Keywords: Factors; Cognitive development; Proportion

\footnotetext{
* Corresponding author: Obadia V Nyongole

School of Medicine, Muhimbili University of Health and Allied Sciences. 


\section{Introduction and literature review}

Cognitive development is defined as thinking, concept understanding, information processing, problem solving and overall intelligence. Cognitive development reflects the way one perceives, thinks, performs or interacts with the environment or other people. Cognitive development and development in its totality, that is achieved in the first two years of life is very important in the future life of an individual. Early cognitive development goes together with growing capacities to explore the environment, make sense of the world, and discover a sense of self in the world. Cognitive development is directly connected to the development of emotions, language and physical development. Genetic and environmental factors determine the development of a child. The environment in which the infant is raised in and interactions with it contribute to the child's intellectual ability including connection of previous experiences with new information and newly acquired skills [1].

Emotional and cognitive functioning are strongly affected by what happens in the first few years of life (especially the first two years of life) and mostly in the first year of life. Checks in ECD can predict development of disability, incarceration, mental illness, or substance abuse in future. There are simple and affordable interventions that can be used in early life to prevent or reduce the severity of consequences of delay in cognitive development [2].

Development of cognition is very important to the development of attachment. Infants demonstrates it by imitating adult facial expressions, smile in response to baby games, repeats chance behaviours that lead to pleasurable and interesting results, and recognize familiar people, places and objects. This starts at early infancy and grows with age. By the end of the first year, infants deliberately look to others for emotional cues and evaluate uncertain events, such as, the approach of a stranger though they cannot describe their feelings. Although vocalizations and body movements provide some information, facial expression offers the most reliable cue during the age of 18-24 months. Cross-cultural evidence indicates that when infants in different parts of the world are looking at photographs of different facial expressions they associate them with emotions in the same way. The pragmatic movements in the field of speechlanguage pathology influenced by social-cognitive learning theory re-established the idea that language is embedded in a social matrix. This movement tells us that children do not talk about objects of interest in isolation but communicate in the context of social interactions often for socially and emotionally driven reasons [3-4].

It is estimated that more than 200 million children under 5 years fail to reach their potential in cognitive development worldwide. Mostly because of poverty, poor health and nutrition, and deficient care. Children's development consists of several interdependent domains. These includes sensory-motor, cognitive and social-emotional, all of which are likely to be affected. In late childhood these children will subsequently have poor levels of cognition and education, both of which are linked to later economical potential [5-7].

Up to $10 \%-13 \%$ of children have delayed milestones worldwide. Most of these affected children (80\%) live in south Asia and sub-Saharan Africa. A longitudinal study done by Steven et al in United States on children at the age of 9-24 months reported developmental delays of 13\%. Only $10 \%$ of those with delayed milestones receive health related services. These disadvantaged children are likely to do poorly in school and therefore have low incomes, high fertility, and provide poor care for their children, thus vicious cycle of poverty. It is possible for these adverse effects to be prevented. The second UN Millennium Development Goal is to ensure that all children get primary school education, so early child development is mandatory in achieving this goal [5,8-11].

Many factors can disrupt early child development. Socio-demographic characteristics and maternal care giving (especially 'opportunities for stimulation') have been identified as significant predictors of all child outcomes. Sylva et al in the study done in the United kingdom on children at 18months of age reported non-maternal care giving is significantly associated with cognition delay. Among the factors that may predict delayed cognitive development is the age of the parents or care taker. In particular the age of the mother, it has been shown that, young mothers $(<18 y r s$ of age) and those with old age $(>35)$ have been associated with poor cognition of their children. Andrew et al in Australia reported poor cognition with young mothers [12-15].

From the studies done by Leibowitz et al and Lehrer in Washington and Canada respectively, reported that, the bigger the size of the family the higher the risk of developmental delay of children. It was also found that, the balance between the family levels of need for child care i.e. the number of young children in the household compared to the number of available supportive adults in the household is associated with the selection of non-parental care [16-18].

Brooks-Gunn et al in Newyork, in their study showed that, the rate at which infants enter non-parental care appears to be higher for smaller families. However, the rate at which this family-size effect occurs is not well understood. Cost considerations become more potent as family size grows, causing more and more mothers, not eligible for subsidies, to 
stay at home. Burchinal et al reported no relationship between cognition and maternal employment in the first 3years of life [19-20].

Improved parental education, especially of mothers, is related to reduced fertility and improved child survival, health, nutrition, cognition, and education. Education may serve as a proxy for health literacy associated with child-rearing behaviors (e.g., breastfeeding, reading to the child). Education also reflects the social class i.e. financial and material resources needed to assure the child receives adequate nutrition, receives high quality child care, (if needed) and obtains needed health-related services. Social class may further influence child health through the effect of relative social position that may impact family stress, parent self-esteem, empowerment, and life control [21-24].

Better educated parents are consistently more likely to place their children in non-parental care. In US, among families national wide with children ages 3-5, 48\% were in non-parental care when one parent's highest schooling level was less than a secondary school diploma, versus $72 \%$ when one parent had attended some college. In US, only $46 \%$ of Latino families use non-parental care for children under age 5, in comparison to $64 \%$ for White families and $75 \%$ for Black families. The difference between Latino and non-Latino families is most pronounced among those families who speak Spanish at home. This difference is due to the fact that Latino women are less likely to be employed, either part time or full time. The differences across ethnic communities in the organized supply of centers or family day-care homes may further contribute to differences in the rate of selecting non-parental care [25-28].

A comparison study which was done in India on children aged 1-2 years revealed that male and female were equally developing in cognition. The study done by Mc Donald showed that, infant's cognition improves steadily with age and decrease attention to repetitive stimulation. Fergusson et al did a study on children in the first 7years of life and found that, children who were breastfed for a minimum of 3 to ` 5 months as compared to those who were bottle-fed had an advantage of between 0.15 and 0.25 SD units in mean test performance, even after control for confounders. From the studies done by Morley et al and Lucas et al on feeding practices among preterm infants, it was shown that, children whose mothers chose to express their own milk to feed their infant had higher developmental scores at 18 months and higher intelligence quotient assessed at 7.5 to 8.0 years than those whose mothers chose not to do so even after control of confounders of development and cognition as well. The improved cognitive abilities of breastfed children may involve long chain polyunsaturated fatty acids and, particularly, docosahexaenoic acid (DHA). Clinical studies in which infant formula was supplemented with DHA suggested possible improvements in visual acuity and cognitive ability in preterm infants given the DHA-supplemented formula. In general, research is beginning to provide a compelling case for the view that breastfeeding may have longer-term effects on individual cognitive ability and educational achievement. Children very preterm and free of severe disabilities had mild delays in multiple areas of development [3,29-35].

HIV exposure and infection has been reported in several studies to have an effect on cognitive development in children. Christopher et al in the comparable longitudinal study done in Pretoria-south Africa on 255 infants, found that, HIVexposed infants have cognitive development delay $(\mathrm{p}=0.003)$. Studies done by Drota et al and Van Rie et al in Uganda and Kinshasa- DRC respectively found that cognitive developmental delay is based on HIV status and not exposure. Springer in the study done in South Africa on 17 HIV-exposed and 20 HIV-unexposed infants found no difference between the two groups [36-40].

Studies in Latin America reported poverty and malnutrition are related to poor health and increased mortality with less recognition of their effect on children's development or of the value of early intervention. Proteins, carbohydrates and fats through metabolic process act as building blocks of brain hence influence cognitive development. Cross-sectional studies in Nepal, Ghana and Tanzania reported stunted children being enrolled to school late. Further studies done in Kenya, Guatemala and Ethiopia reported that stunting is associated with poor cognition. However some studies done in Philippines and Ghana found no significant difference on stunting in relation to poor school performance. Weight for age instead of length/height for age has been used in measuring nutrition status in young children and association was reported in the studies done in India, Bangladesh and Ethiopia [6-7,41-50].

Several interventions have been pointed out. Examples of these interventions are improving child nutrition, early child education, providing a stimulating environment, parenting training and adult education. Young children need to spend time in a caring, responsive environment that protects them from neglect and inappropriate disapproval and punishment. Parents and families are the key to early child development, but need support to provide the right environment. Children benefit when national governments adopt "family friendly" social protection policies that guarantee adequate family income, maternity benefits, financial support, and allow for parents and caregivers to devote time and attention to young children. Worldwide, societies that invest in children and families in the early years whether rich or poor - have the most literate and numerate people. These are also the societies that have the best health status and lowest levels of health inequality in the world. Early child development (ECD) interventions provide direct 
learning experiences to children and families. They are targeted to young and disadvantaged children, high quality and long lasting, integrated with family support, health, nutrition, or education systems and services. The health care system and health providers have roles to play, as they are often the points of early contact with a child and can serve as gateways to other early childhood services. Health care workers are trusted sources of information for families and can give critical guidance about: how to communicate with infants and children, ways to stimulate children for better growth, how to handle such common developmental problems as sleep, feeding and discipline and ways to reduce common childhood injuries[51-55].

Our study aimed to determine the proportion and factors associated with cognitive developmental delay among infants attending RCH clinics in Dar es Salaam from July to December 2012.

\section{Material and methods}

Study design; This was a health facility-based descriptive cross sectional study to determine factors associated with cognitive developmental delay in infants who attended RCH clinics at Magomeni, Buguruni and Kigamboni health centers in Kinondoni, Ilala and Temeke municipals respectively in Dar es Salaam from.

Sampling technique; Two-stage random sampling technique was done. The lists of all public health centres in the three municipals of Dar es Salaam were obtained. Using lottery method one health centre was selected from each municipality. Data collection was done on weekly rotation to the three health centres. A list of all infants aged 1 to $12 \mathrm{months}$ who registered in the RCH clinics on the day of data collection i.e. Tuesdays and Fridays was obtained. Public holidays were excluded. Odd-numbered infants were invited to participate in the study. History and physical examination was performed by the investigator as routine. Only those who met the inclusion criteria were interviewed until a sample of approximately 50 was reached in each age group (ie $2,4,6,8,9,10,12+/$ - 30days) was attained.

Inclusion criteria; Infants aged 1 to 12 months with parental/caretaker consent were included

Exclusion criteria; Children with obvious severe congenital malformations,Severe acute illness i.e. high grade fever, convulsion, loss of consciousness, respiratory distress and acute diarrhoea with signs of dehydration at the time of interview. NB: These conditions were excluded because it is difficult to differentiate those with developmental delay versus illness. Also those with acute illness needed urgent treatment.

\subsection{Data collection and analysis}

A structured questionnaire was used to collect the following information: smoking habit, maternal age, duration of breastfeeding, paternal education level, number of under-fives in the family, maternal education and family size were inquired. Also age of the child, gestation age (term/preterm), birth weight, current body weight, sex, birth order and bad experiences including birth asphyxia/history of illnesses were recorded. Participants were weighed using a 25 kilogram Salter hanging scale (Weighing equipment, High Holborn, London, United Kingdom) with a child putting on light cloths and no shoes. A standard beam balance (SECA) was used in weighing the young infants. The readings were recorded to the nearest $0.1 \mathrm{~kg}$. Calibration of weighing scale to zero was performed each day of recruitment. A known $1 \mathrm{~kg}$ weight was used to standardize the scales every day for accuracy and consistency.

Length of the participants was measured using a length board. Parents/guardians assisted in removing shoes and gently laying the child in supine position on the board, with their heads placed at 900 to the fixed head piece. The investigator straightened the legs of the child at the knees and ensured that feet were at right angle to the sliding foot piece which was brought into contact to the child's heels. The length was recorded to the nearest 0.1 centimeters. Interpretation of nutritional status Using "Epi Nut" programme on the "Epi Info" statistical package version 6.04d, Z-scores for Weight for Length (WHZ), weight for age (WAZ) and length for age (LAZ) were calculated. For the purpose of this study Z Scores were interpreted as follows: Z- Between Mean \& -2SD: Normal nutritional status, Z - below -2SD: wasting/underweight/stunting

Cognitive development screening was done by using ages and stages questionnaire 3rd edition (ASQ-3).58 This screening tool has communication, gross motor, fine motor, problem solving and personal social components. It has 21 age-specific questionnaires that are aimed at assessing child development of infants and young children up to $5 y e a r s$ of age. Each questionnaire is valid for \pm 1 month. Each developmental component has 6 items that are responded in 3 levels: 'Yes','Sometimes, or 'Not yet', which are scored as 10, 5, or 0 respectively. There are different cut off points in different age groups (<2SD) on each component. Validity 0.86 , sensitivity $86 \%$ specificity $85 \%$ was reported in US57. The tool has also been validated in India in 200 children where the overall sensitivity of ASQ for detecting developmental delay 
was 83.3\% and specificity was 75.4\%. 59 Several other studies have been done on Ages and Stages Questionnaire and showed that it is less cost parent-administered questionnaire that is reliable for both risky and low-risk children58-63. This screening tool has been used across the world for more than 15 years .In this study only the problem solving part was used. A caregiver who knew the child well responded to the ASQ-3 together with structured questionnaire. In addition the infants were given some task to perform during the interview especially when the reporter was not sure. Each infant was assessed for 20-30 minutes. Children who scored below the cut-off score were considered having cognitive developmental delay, therefore need for further assessment by professionals; those whose scores lie close to cut-off score needed close follow-up and those lying above the cut-offs were considered developing normally. The latter two groups were considered not having delayed cognitive development. The cut-off points for different age groups differed.

\subsection{Data analysis}

Data were entered into computer for analysis where by SPSS version 16 was used to analyze the information. Crosstabulations were generated, and where comparisons were made, significance was considered at p-value of less than 0.05. The association between cognitive developmental delay (dependent variable) and the independent variables was obtained through Pearson's chi-square and Fisher's exact for the categorical variable. Univariate logistic regression was used in variable with more than two categories. Multivariate logistic regression was used to adjust for confounders and all independent variables with a p-value less than 0.2 were included.

\subsection{Ethical issues}

Permission to conduct this study was sought from Institutional Review Board of Muhimbili University of Health and Allied sciences (MUHAS) and from the three municipals administration (i.e. district medical officers). Parents/caretakers of participants signed a written informed consent prior to recruitment. No Infants were denied from services for not participating in our study. Children who were found to have cognitive developmental delay were referred to Muhimbili National Hospital for follow-up and further assessment. All participants' informations were kept confidential.

\subsection{Study limitations}

The findings of this study may not reflect the true picture of infant's cognitive developmental delay in Dar es Salaam as only three public health centers were involved. Also Infants whom did not attend the clinics during the study period missed the opportunity to participate therefore underestimate the proportion of the problem. Moreover the tool used in assessment of cognitive developmental delays was not validated in our setting.

\section{Results}

A total of 350 infants were assessed, majority of them 177 (50.6\%) were males. Our study Participants aged 1 to 12 months with a mean (SD) of 7.26 (3.43) months with their birth weight ranging from 1.3 to $4.6 \mathrm{~kg}$ with mean (SD) of $3.11(0.50) \mathrm{kg}$, most of them (99.2\%) were term at birth.

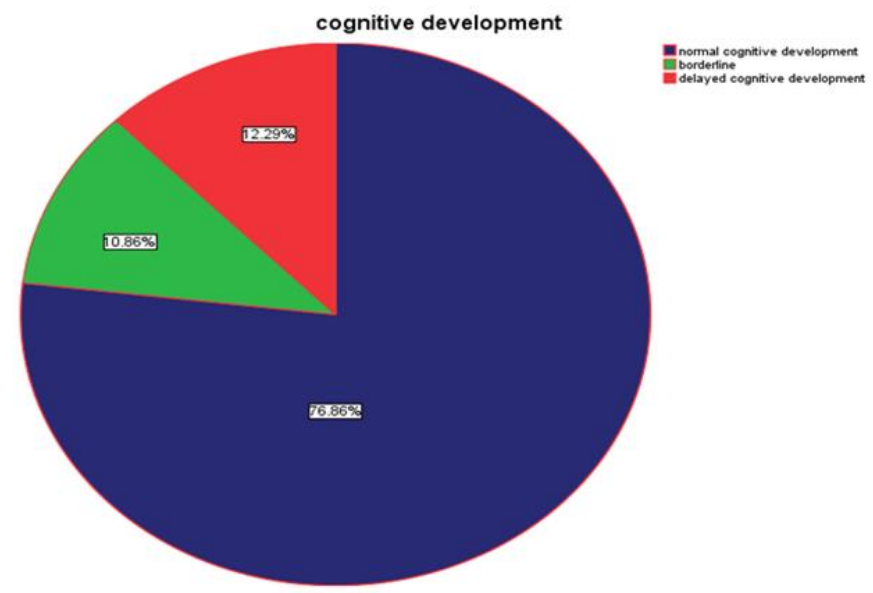

Figure 1 Proportion of infants with cognitive developmental delay 
Majority (94.3\%) of them were still breast feeding most of mothers (90.8\%) aged 19 to 35 years with the mean (SD) of 26.33 (5.17). Most of the parents had a maximum of seven years of schooling. The assistant caretakers' age ranged from 9 to 74 years with the median age of 19years. [Table 1] The Proportion of infants with cognitive developmental delay was $12.3 \%$. [Figure 1].

Table 1 Participants characteristics and cognitive developmental delay on chi-square (N=350).

\begin{tabular}{|c|c|c|c|}
\hline Variable & No cognition delay n (\%) & Cognition delay n (\%) & p-value \\
\hline \multicolumn{4}{|l|}{ Sex } \\
\hline Male & $156(88.1)$ & $21(11.9)$ & 0.808 \\
\hline Female & $151(87.3)$ & $22(12.7)$ & \\
\hline \multicolumn{4}{|l|}{ Age (months) } \\
\hline$<6$ & $98(74.8)$ & $33(25.2)$ & $<0.001$ \\
\hline$\geq 6$ & $209(95.4)$ & $10(4.6)$ & \\
\hline \multicolumn{4}{|l|}{$\times$ Birth weight $(\mathrm{kg})$} \\
\hline$<2.5$ & $20(74.1)$ & $7(25.9)$ & 0.004 \\
\hline$\geq 2.5$ & $285(88.8)$ & $36(11.2)$ & \\
\hline \multicolumn{4}{|l|}{ "Bad experience } \\
\hline No & $274(89.8)$ & $31(10.2)$ & 0.002 \\
\hline Yes & $33(73.3)$ & $12(26.7)$ & \\
\hline \multicolumn{4}{|l|}{ Use of assistant caretaker } \\
\hline No & $264(90.4)$ & $28(9.6)$ & 0.001 \\
\hline Yes & $43(74.1)$ & $15(25.9)$ & \\
\hline \multicolumn{4}{|l|}{ HIV exposure } \\
\hline Yes & $29(85.3)$ & $5(14.7)$ & 0.072 \\
\hline No & $275(87.8)$ & $38(12.2)$ & \\
\hline $\begin{array}{l}\text { Weight for length(z-score) } \\
<-2 \text { sd } \\
>-2 \text { sd }\end{array}$ & $\begin{array}{l}25(78.1) \\
282(88.7) \\
\end{array}$ & $\begin{array}{l}7(11.9) \\
36(11.3)\end{array}$ & 0.090 \\
\hline $\begin{array}{l}\text { Length for age(z-score) } \\
<-2 \text { sd } \\
>-2 \text { sd }\end{array}$ & $\begin{array}{l}83(87.4) \\
224(87.8) \\
\end{array}$ & $\begin{array}{l}12(12.6) \\
31(12.2)\end{array}$ & 0.904 \\
\hline $\begin{array}{l}\text { Weight for age(z-score) } \\
<-2 \text { sd } \\
>-2 \text { sd }\end{array}$ & $\begin{array}{l}15(75.0) \\
292(88.5)\end{array}$ & $\begin{array}{l}5(25.0) \\
38(11.5)\end{array}$ & 0.090 \\
\hline $\begin{array}{l}\text { Family size(people) } \\
\leq 5 \\
>5\end{array}$ & $\begin{array}{l}259(89.0) \\
48(81.3)\end{array}$ & $\begin{array}{l}32(11.0) \\
11(28.7)\end{array}$ & 0.107 \\
\hline & $\begin{array}{l}\text { NB; Bad experience includes any } \\
\text { history of recurrent illness/birth } \\
\text { asphyxia }\end{array}$ & & \\
\hline
\end{tabular}

The third born child was 2.5 times more likely to have cognitive developmental delay compared to the first born; (OR 2.5; 95\%CI 1.1-6.0, p=0.035). However, it was no longer significant with fourth born or more. When the age of the assistant caretaker was above 35yrs the likelihood of infant cognitive developmental delay was 9.8 times more likely than when the age was 19-35yrs (OR 9.8; 95\%CI 1.1-92.7, p=0.001). However, there was no significant difference in infants cognitive developmental delay when the caretakers' age of <18years compared to 19-35years. [Table 2]. 
Table 2 Univariate analysis on the factors associated with cognitive developmental delay.

\begin{tabular}{|l|l|l|l|l|}
\hline Variable & $\begin{array}{l}\text { No cognition } \\
\text { Delay n(\%) }\end{array}$ & $\begin{array}{l}\text { Cognition } \\
\text { Delayed n(\%) }\end{array}$ & P-value & $\begin{array}{l}\text { Crude } \\
\text { OR(95\%CI) }\end{array}$ \\
\hline Birth order & & & & \\
$1^{\text {st }}$ born & $138(97.2)$ & $4(2.8)$ & & 1 \\
$2^{\text {nd }}$ born & $98(88.3)$ & $13(11.7)$ & 0.510 & $1.3(0.6,2.9)$ \\
$3^{\text {rd }}$ born & $43(79.6)$ & $11(20.4)$ & 0.035 & $2.5(1.1,6.0)$ \\
$\geq 4^{\text {th }}$ born & $27(84.4)$ & $5(15.6)$ & 0.313 & $1.8(0.6,5.3)$ \\
\hline No. Of under fives & & & & \\
1 & $230(89.1)$ & $28(10.9)$ & & 1 \\
2 & $71(86.6)$ & $11(13.4)$ & 0.527 & $1.3(0.6,0.7)$ \\
3 & $6(60.0)$ & $4(40.0)$ & 0.120 & $5.5(1.4,20.6)$ \\
\hline Mother's age(years) & & & & \\
$19-35$ & $278(87.4)$ & $40(12.6)$ & & 1 \\
$<18$ & $14(93.3)$ & $1(6.7)$ & 0.504 & $0.5(0.1,3.9)$ \\
$\geq 36$ & $15(88.2)$ & $2(11.8)$ & 0.921 & $0.9(0.2,4.2)$ \\
\hline$*$ Assistant caretaker age (years) & & & & \\
$19-35$ & & & & \\
$<18$ & $14(93.3)$ & $1(6.7)$ & & 1 \\
$\geq 36$ & $19(73.1)$ & $7(26.9)$ & 0.601 & $1.7(0.2,13.6)$ \\
& $10(58.8)$ & $7(41.2)$ & 0.046 & $9.8(1.1,92.7)$ \\
\hline Mother's employment & & & & \\
housewife & $4(66.7)$ & $2(33.3)$ & & 1 \\
Not employed & $17(77.3)$ & $5(22.7)$ & 0.597 & $0.6(0.1,4.2)$ \\
$* *$ Formal employment & $110(89.4)$ & $13(10.6)$ & 0.115 & $0.2(0.0,1.4)$ \\
peasant & $161(88.5)$ & $21(11.5)$ & 0.134 & $0.3(0.0,1.5)$ \\
$* * *$ others & $15(88.2)$ & $2(11.8)$ & 0.249 & $0.3(0.0,2.5)$ \\
\hline Father's employment & & & & \\
Works daily & $277(91.1)$ & $27(8.9)$ & & 1 \\
Not employed & $6(85.7)$ & $1(16.3)$ & 0.701 & $1.5(0.2,13.1)$ \\
peasant & $3(60.0)$ & $2(40.0)$ & 0.053 & $6.1(0.9,38.1)$ \\
$* * *$ others & $51(79.7)$ & $13(20.3)$ & 0.220 & $2.3(1.1,4.8)$ \\
\hline
\end{tabular}

**Professional/business/petty trader = formal employment; ${ }^{*}$ Assistant caretaker $=$ the person who stayed with the infants whom their mother were absent, especially during the day; ${ }^{*}$ Work daily= Professional/business/petty trader/driver ${ }^{* * *}$ others $=$ day workers, no formal employment

Age of the child, caretakers and wasting were significantly associated with cognitive developmental delays even after adjusting for confounders. Infants aged less than 6 months were 14 times more likely to have cognitive developmental delay compared to those aged six months and above (aOR=14; 95\%CI 5.3-38.3, $\mathrm{P}<0.001)$. Infants cared by assistant caretakers especially during day-time, were 12 times more likely to have cognitive developmental delay compared to infants who stayed with their mothers (aOR=12.1; 95\%CI 3.0-53, $\mathrm{P}=0.001)$. Wasted infants were 4 times more likely to have cognitive developmental delay (aOR=3.9; 95\%CI 1.1-13.3, $\mathrm{P}=0.032)$ compared to infants with good nutritional status [Table 3]. 
Table 3 Predictors of infants' cognitive developmental delay (multivariate analysis).

\begin{tabular}{|l|l|l|}
\hline Variables & Adjusted OR(95\% CI) & P-value \\
\hline Age(Months) & & \\
\hline$<6$ & $14.2(5.3,38.3)$ & $<0.001$ \\
\hline$>6$ & 1 & \\
\hline Use of assistant caretaker & & \\
\hline No & 1 & \\
\hline Yes & $12.1(3.0,52.0)$ & 0.001 \\
\hline Number of under-fives & & \\
\hline 1 & 1 & \\
\hline 2 & $0.1(0.0,0.5)$ & 0.008 \\
\hline 3 & $0.1(0.0,0.5)$ & 0.013 \\
\hline
\end{tabular}

\section{Discussion}

Early child cognitive development (ECD) which occurs in the first two years of life and mostly in infancy is very important in ones later life. In our study the proportion of infants with cognitive developmental delay was $12.3 \%$ of the studied infants; this is similar to a study by Gregory et al and Rosenberg et al, in under-fives with $10 \%$ and $13 \%$ developmental delay respectively $[5,8]$. Our study findings are likely to underestimate the problem in the general population because this study was done in a well-baby clinic and a primary level of health care where those with problems might have been referred to higher levels. However, the explanation can also be, infants who attend the wellbaby clinics are more likely to have access to the health services, including health education, and low risk of developmental delays.

We found no significant sex difference in relation to infants' cognitive developmental delay similarly to what was reported in the comparison study done in children aged 1-2 years by Bimla and Sudha in India [29]. Also the developmental delay significantly decreased with increasing age $(\mathrm{p}<0.001)$ this was reflected in a study by Donald et al which that reported that it could be due to retention of memory with repetitive stimulation [3].It can also be due to the cultural aspect as usually young children are mostly kept indoors and therefore less exposure and stimulation. Low birth weight showed a tendency of cognitive developmental delay although there was no significant difference after adjusting for confounders ( $\mathrm{p}=0.061$ ) contrary to what was found by Georgrieff et al whereby low birth weight was significantly associated with poor cognition $(\mathrm{p}=0.008)[6]$.

Third born child was found to be 2.5 times more likely to have cognitive developmental delay compared to the first born in the current study; although the significance disappeared after adjusting for the confounders in multivariate analysis. This finding was contrary to the study in South Africa by Christopher et al which found no difference in cognition on first born child versus subsequent [36].

Parental/caretaker excitement following having a child as the first experience has probably more stimulation compared to subsequent infants which may explain this. Increasing number of children to four or more the difference disappears. This may be due to increased parental experience and stimulation from the other siblings as they grow older.

HIV exposed but uninfected infants showed a tendency of increased cognitive developmental delay compared to HIVunexposed infants but this was not statistically significant in this study. This finding is consistent with the study by Springer et al 40 which reported no difference in cognition between the two groups although the later study had very small sample size (17 exposed versus 20 infants unexposed) [40]. However, studies by Filteran et al and Christopher et al found cognitive delays in HIV-exposed but uninfected compared to HIV-unexposed infants. The difference may be because the later studies were longitudinal, using Bayley scale for infants and toddlers 3rd edition (BSID-III) compared to the current study which was cross-sectional with ASQ-3 which have slight lower sensitivity and specifity[36-37,58]. 
Wasting unlike low weight for age was significantly associated with cognitive developmental delay in our study this is similar to what was found by Kasasa et al in a study done in high risk infants in Dar es Salaam [65] but contrary to the longitudinal studies done in Ethiopia and Bangladesh by Brewet et al and Hamadan respectively[49-50]. Deficiency of the macronutrients i.e. proteins, carbohydrates and fats leading to inadequate raw materials for the brain development explains this [41]. We also found that there was no significant difference in cognition among stunted infants compared to non-stunted infants. Similarly to the findings in Philippines and Ghana, although these were done in older children [46-47]. However, cross sectional studies with larger sample size done in Kenya, Guatemala and Ethiopia reported significant association between stunting and cognition [44-45]. Since weight for age represents a combination of stunting and wasting, the mechanism cognition delay in wasting and not stunting is unknown.

Use of assistant caretaker during the day-time in this study was significantly associated with cognitive developmental delay even after adjusting for confounders. Similar findings were reported in the longitudinal study done on children at 18month of age by Sylva et al [12].Infants learn through interaction with familiar adults as well as peers by imitating facial expressions hence the importance of stimulation [3].Absence of the mother when these infants are awake may have lead to missed opportunity for them to learn adequately. In addition around $45 \%$ of the caretakers were less than 18years of age. It is "children taking care of children". The low education, less or no experience and probably burden of home activities that lead to less interaction with the infants can explain the difference observed.

When the age of the assistant caretakers was greater than 35years or less than 18years of age, the risk of infant cognitive developmental delays were higher compared to those with 19-35years. Studies done by Harvey et al and Goldenberg et al reported that young and old age are related to cognitive development delay with statistical significance [13-14]. Another study in Australia by Andrew et al reports poor cognition with young maternal age15 this explained that age may be related to maternal care giving experience [15].

There was no statistical difference on cognitive developmental delays with regard to the number of under-fives in the family in the current study after adjusting for confounders. The study done by Leibowitz et al and Lehrer in Washington and Canada on pre-school children reported statistical difference on cognition delay with increasing number. These have been explained by the imbalance between the number of caretakers/adults and infants in need of care16. In our case, the difference may have been masked by the cultural difference together with extended family. It is easier to distribute the infants to the other family members for care $[16,18]$.

Our study also found that maternal employment was significantly protective in infant cognitive developmental delay similarly to the findings by Burchinal et al in an analytical study that reported maternal employment was not related to cognitive ability in the first 3years of life [20]. This were controversial findings since mothers who are employed are the ones not staying with their children especially during the day time. On the other hand employed mother are more likely to be educated and therefore good health care practices/services to their children which may have counteracted the developmental delays.

Reported breast feeding duration in this study had no difference in terms of the infant cognitive development. This is contrary to several studies which reports significantly higher developmental scores in children who were breastfed for at least 3months [30-32,64]. These studies were longitudinal with large sample sizes hence making them more reliable compared to the current study [65]. However, majority (94.3\%) of infants in the current study were still breastfeeding hence less likely to show the difference.

\section{Conclusion}

The proportion of cognitive developmental delay among infant attending RCH clinics in Dar es Salaam is $12.3 \%$. Younger age of the child, use of other caretakers in absence of the mother and wasting were significantly associated with cognitive developmental delays even after adjusting for confounders. Parents whose infants' are under assistant caretakers should try as much as possible to spend quality time with them .All infants should be assessed on cognitive development during their visit to RCH clinics with more emphasis on the above mentioned risk factors for early detection and intervention of cognitive developmental delay. We recommend for a community based, follow up study to measure the magnitude of cognitive developmental delays and look at the causal relationship of the associated factors and therefore better interventions. 


\section{Compliance with ethical standards}

\section{Acknowledgments}

We would like to extend our sincere gratitude and appreciation to the Ministry of Health and Social Welfare for sponsoring this study without conflict of interest known to us. We will always be indebted to all the infants who participated in this study and very thankful to their parents/guardians who gave consent on their behalf. We would also like to thank all the nurses working at the RCH clinic at Magomeni, Kigamboni and Buguruni health centers for all the assistance and support they accorded me during data collection.

\section{Disclosure of conflict of interest}

The authors declare no competing interests.

\section{Authors' contributions}

GVS: designed the study, collected data, performed data analysis and wrote the report.

OVN; Participated in the study design and manuscript preparation.

$\mathrm{AM}$ and GK participated in the study design and Review of the report.

\section{Statement of informed consent}

Informed consent was obtained from all mothers of infants who were included in the study.

\section{References}

[1] Smith AK. From Piaget to Cognitive Neuroscience. A Scientific Workshop in Honour of Professor Annette Karmiloff-Smith. Development Unit at London's Institute of Child Health (ICH) in. 2004; (2003).

[2] Strathearn L, Gray P, Callaghan M, Wood D. Childhood Neglect and Cognitive Development in Extremely Low Birth weight Infants: A prospective Study. Pediatrics. 2000; 108(1): 142-151.

[3] Mc Donald JL. Language acquisition: The acquisition of linguistic structure in normal and special populations. Ann. Rev. Psychol.1997; 48: 215-241.

[4] Klein HB, Moses N. Intervention Planning for Children with Communication Disorders: A Guidefor Clinical Practicum and Professional Practice. Prentice Hall, New Jersey. 1994.

[5] Grantham-McGregor S, Cheung YB, Cueto S, Glewwe P, Richter L, et al. Child development in developing countries 1: developmental potential in the first 5 years for children in developing countries. Lancet. 2007; 369: 60-7.

[6] Hatt LE, Waters HR. Determinants of child morbidity in Latin America: a pooled analysis of interactions between parental education and economic status. Soc Sci Med. 2006; 62: 375-386.

[7] Steven A Rosenberg, Duan Zhang, Cordelia C Robinson, et al. Prevalence of Developmental Delays and Participation in Early Intervention Services for Young Children. Paediatrics 2008; 121(6): e1503-e1509.

[8] Rosenzweig MR, Wolpin KI. Are there increasing returns to the intergenerational production of human capitalmaternal schooling and child intellectual achievement? J Hum Res. 1994; 29: 670-693.

[9] Engle PL, Black MM, Behrman JR, Cabral de Mello M, Gertler PJ, et al. Strategies to avoid the loss of developmental potential in more than 200 million children in the developing world. Lancet. 2007; 369: 229-242.

[10] UN Road map toward the implementation of the United Nations Millennium Declaration. United Nations; New York: 2002. United Nations General Assembly Document A56/326.

[11] Sylva K, Stein A, Leach P, Barnes J, Malmberg LE. team. Effects of early child-care on cognition, language, and taskrelated behaviours at 18 months: an English study.UK J. Dev. Psychol. 2011; 29: 18-45.

[12] Harvey D, Prince J, Bunton J, Parkinson C, Campbell S. Abilities of children who were small for gestational age babies. Pediatrics. 1982; 69(3).

[13] Goldenberg RL, DuBard MB, Cliver SP, Nelson KG, Blankson K, Ramey SL, Herman A. Pregnancy outcome and intelligence at age five years. A mJ Obste. Gynecol. 1996; 175(6): 1511-1515. 
[14] Leibowitz A, Waite L, and Witzberger C. Child care for preschool. Difference by child age, Demography1988; 25:205-220

[15] NICHD. Early Child Care Research Network. Before Head Start: income and ethnicity, family characteristics, child care experiences and child development. Early Educ Dev 2001; 12: 545-76.

[16] Lehrer E. Determinants of child care mode choice. An economic perspective. social science research. 1983; 12: 69-80.

[17] J Brooks-Gunn, G Duncan. Poverty and the pattern of child care. Consequences of growing up poor in Newyork. Future of children. 1997; 7: 55-71.

[18] Burchinal MR, Clarke-Stewart KA. Maternal employment and child cognitive outcome. The importance of analytical approach. Dev. Psychol. 2007; 43(5): 1140-55.

[19] Maitra P. Effect of socioeconomic characteristics on age at marriage and total fertility in Nepal. J Health Pop Nutr. 2004; 22: 84-96.

[20] Lam D, Duryea S. Effects of schooling on fertility, labor supply, and investments in children, with evidence from Brazil. J Hum Res. 1999; 34: 160-192.

[21] Szilagyi P, Schor E. The health of children. Health ServicesResearch 1998; 33(4 Pt. 2): 1001-1039.

[22] Starfield BUS. child health: what's amiss, and what should be done about it? A strong primary care infrastructureis key to improving and reducing disparities in children's health. Health Aff (Millwood). 2004; 23(5): 165-170.

[23] West J, Hausken E, Collins M. Profile of preschool children's child care and early education programme experience.NCES. 1993; 93-133.

[24] Hofferth S, West J, Henke R, Kaufman S. Access to daily childhood programs for children at risk, Washington DC. National Center Education Statistics. 1994; 93-372.

[25] Liang X. Economic constraints, parental beliefs or ethnicity? Explaining preschool enrolment in America. Unpublished doctoral dissertation, Havard university. 1996.

[26] Folk K, Beller A. Part time work and child care choices for mothers of preschool children. Journal of marriage and family. 1993; 55: 146-157.

[27] Bimla Dhnda, Sudha Chhikara. Early cognitive development of babies of rural and urban Hisar. Anthropologist. 2008; 10(4): 309-311.

[28] Fergusson DM, Beautrais AL, Silva PA. Breast-feeding and cognitive development in the first seven years of life. Soc Sci Med. 1982; 16: 1705-1708.

[29] Morley R, Cole TJ, Powell R, Lucas A. Mother's choice to provide breast milk and developmental outcome. Arch Dis Child. 1988; 63: 1382-1385.

[30] Lucas A, Morley R, Cole TJ, Lister G, Leeson-Payne C. Breast milk and subsequent intelligence quotient in children born preterm. Lancet. 1992; 339: 261-264.

[31] Morley R. Diet in infancy and developmental outcome. Semin Neonatol. 1996; 1: 27-34.

[32] Carlson SE, Werkman SH, Peeples JM, Wilson WM. Long-chain fatty acids and early visual and cognitive development of preterm infants. Eur J Clin Nutr. 1994; 48 (suppl 2): S27-S30.

[33] ML Charkaluk, P Truffert A Fily, PY Ancel, V Pierrat. Epipage study group1 Neurodevelopment of children born very preterm and free of severe disabilities: the Nord-Pas de Calais Epipage cohort study.

[34] Christopher G, Anand S, Jeniffer M, Iriva B, Bnan F. Neurodevelopment of HIV-exposed infants but non-infected (South Africa).

[35] Filtean S, et al. The HIV-exposed uninfected African child. Trop. Medicine and Intl Health. 2009; 14(3): $276-287$.

[36] Drotar D, Olness K, Wiznitzer M, et al. Neurodevelopment outcomes of Ugandan infants with human immunodeficiency virus type 1 infection. Paediatrics. JULY 1997; 100(1): E5.

[37] Van Rie A, Dow A, Mupuala A, Nossa N, Zephyrin I. Neurodevelopment of HIV infected and HIV affected children in Kinshasa, DRC. Pediatrics. 2008; 122: e123-8. 
[38] Springer et al. Neurodevelopment status of HIV-exposed but uninfected children. A pilot study. S.Afr J. CH. 2012; 6(2): 51-55.

[39] Kliegman RM, Jenson HB, Behrman RE. Stanton BF. Nelson textbook of pediatrics. 18th ed. 2008; 1: 701.

[40] Moock PR, Leslie J. Childhood malnutrition and schooling in the Terai region of Nepal. J Dev Econ. 1986; 20: 3352.

[41] Brooker S, Hall A, Bundy DAP, et al. Short stature and the age of enrolment in primary school: studies in two African countries. Soc Sci Med. 1999; 48: 675-82.

[42] Sigman M, Neumann C, Jansen AA, Bwibo N. Cognitive abilities of Kenyan children in relation to nutrition, family characteristics, and education. Child Dev. 1989; 60: 1463-74.

[43] Johnston FE, Low SM, de Baessa Y, Macvean RB. Interaction of nutritional and socioeconomic status as determinants of cognitive development in disadvantaged urban Guatemalan children. Am J Phys Anthropol. 1987; 73: 501-06.

[44] Popkin B, Lim Ybanez M. Nutrition and school achievement. Soc Sci Med. 1982; 16: 53-61.

[45] Glewwe P, Jacoby H. An economic analysis of delayed primary school enrollment in a low income country: the role of early childhood nutrition. Rev Econ Stat. 1995; 77: 156-69.

[46] Vazir S, Naidu AN, Vidyasagar P. Nutritional status, psychosocial development and the home environment of Indian rural children. Indian Pediatr. 1998; 35: 959-66.

[47] Drewett R, Wolke D, Asefa M, Kaba M, Tessema F. Malnutrition and mental development: is there a sensitive period? A nested case-control study. J Child Psychol Psychiatr. 2001; 42: 181-87.

[48] Hamadani JD, Fuchs GJ, Osendarp SJ, Khatun F, Huda SN, Grantham-McGregor SM. Randomized controlled trial of the eff ect of zinc supplementation on the mental development of Bangladeshi infants. Am J Clin Nutr. 2001; 74: 381-86.

[49] Whaley SE, Sigman M, Neumann C, Bwibo N, Guthrie D, et al. The Impact of Dietary Intervention on the Cognitive Development of Kenyan School Children. The Journal of Nutrition. 2003; 133: 3965S-3971S.

[50] Neumann CG, Murphy SP, Gewa C, Grillenberger M, Bwibo NO. Meat Supplementation Improves Growth, Cognitive, and Behavioral Outcomes in Kenyan Children. The Journal of Nutrition. 2007; 137: 1119-1123.

[51] Raine A, Venables PH, Dalais C, Mellingen K, Reynolds C, et al. Early educational and health enrichment at age 35 years is associated with increased autonomic and central nervous system arousal and orienting at age 11 years: evidence from the Mauritius Child Health Project. Psychophysiology. 2001; 38: 254-266.

[52] Klein PS, Rye H. Interaction - Oriented Early Intervention in Ethiopia: The MISC Approach. Infants and Young Children. 2004; 17: 340-354.

[53] Boivin MJ, Giordani B, Ndanga K, Maky MM, Manzeki KM, et al. Economic advantage and the cognitive ability of rural children in Zaire. J Psychol. 1996; 130: 95-107.

[54] Collard KJ. Iron homeostasis in the neonate. Pediatrics. 2009; 123(4): 1208-16.

[55] Squires J, Bricker D Ages. Stages Questionnaires, Third editions (ASQ-3). 2009, Baltimore, MD: Paul. H. Brookes Publishing Co.

[56] Juneja M, Mugdha M, Rahul J, Siddarth R. Ages and Stages Questionnaire as a Screening Tool for Developmental Delay in Indian Children. Indian Paediatric J. 2011.

[57] Elbers J, Macnab A, McLeod E, Gagnon F. The Ages and Stages Questionnaire: feasibility of use as a screening tool for children in Canada. Can J Rural Med. 2008; 13: 9-14.

[58] Rydz D, Srour M, Oskoui M, Marget N, Shiller M, Birnbaum R, et al. Screening for developmental delay in the setting of a community pediatric clinic: a prospective assessment of parent-report questionnaires. Pediatrics. 2006; 118: e1178-86.

[59] Gollenberg AL, Lynch CD, Jackson LW, McGuiness BM, Msall ME. Concurrent validity of the parent completed Ages and Stages Questionnaires, 2nd Ed with the Bayley Scale of Infant Development in a low-risk sample. Child Care Health Dev. 2010; 36: 485-90.

[60] Skelleren CY, Rogers Y, O'Callaghan MJ. A parent-completed developmental questionnaire: follow up of expremature infants. J Paediatr Child Health. 2001; 37: 125-9. 
[61] Lindsay NM, Healy GN, Colditz PB, Lingwood BE. Use of the Ages and Stages Questionnaire to predict outcome after hypoxic-ischemic encephalopathy in the neonate. J Pediatr Child Health. 2008; 44: 590-5.

[62] Georgieff MK. Intrauterine growth retardation and subsequent somatic growth and neurodevelopment. J. Pediatr. 1998; 133: 3-5.

[63] Bangirana P, John CC, Idro R, Opoka RO, Byarugaba J, et al. Socioeconomic Predictors of Cognition in Ugandan Children: Implications for Community Interventions. 2009; PLoS ONE 4(11): e7898.

[64] Michael et al. Breastfeeding and Child Cognitive Development. Arch Gen Psychiatry. 2008; 65(5): 578-584. 